\title{
Prevention, screening and treatment of colorectal cancer: a global and regional generalized cost effectiveness analysis
}

\author{
Gary M Ginsberg ${ }^{1 *}$, Stephen S Lim', Jeremy A Lauer ${ }^{1}$, Benjamin P Johns', Cecilia R Sepulveda²
}

\begin{abstract}
Background: Regional generalized cost-effectiveness estimates of prevention, screening and treatment interventions for colorectal cancer are presented.

Methods: Standardised WHO-CHOICE methodology was used. A colorectal cancer model was employed to provide estimates of screening and treatment effectiveness. Intervention effectiveness was determined via a population state-transition model (PopMod) that simulates the evolution of a sub-regional population accounting for births, deaths and disease epidemiology. Economic costs of procedures and treatment were estimated, including programme overhead and training costs.
\end{abstract}

Results: In regions characterised by high income, low mortality and high existing treatment coverage, the addition of screening to the current high treatment levels is very cost-effective, although no particular intervention stands out in cost-effectiveness terms relative to the others.

In regions characterised by low income, low mortality with existing treatment coverage around 50\%, expanding treatment with or without screening is cost-effective or very cost-effective. Abandoning treatment in favour of screening (no treatment scenario) would not be cost effective.

In regions characterised by low income, high mortality and low treatment levels, the most cost-effective intervention is expanding treatment.

Conclusions: From a cost-effectiveness standpoint, screening programmes should be expanded in developed regions and treatment programmes should be established for colorectal cancer in regions with low treatment coverage.

\section{Background}

In 2000, colorectal cancer accounted for approximately 579,000 deaths (equivalent to $1 \%$ of all deaths and $8 \%$ of deaths due to malignant neoplasms) worldwide. In burden-of-disease terms, colorectal cancer accounts for $0.38 \%$ of all DALYs and $7.2 \%$ of DALYs due to malignant neoplasms [1]. Geographical disparities in the burden of colorectal cancer are pronounced. For example, colorectal cancer incidence rates are 5-10 times higher in the most developed regions of the world than in developing regions (personal communication, K.Shibuya, World Health Organization).

\footnotetext{
* Correspondence: ginsbergg@moh.health.gov.l
${ }^{1}$ Costs, Effectiveness, Expenditure and Priority Setting, World Health

* Correspondence: ginsbergg@moh.health.gov.l
${ }^{1}$ Costs, Effectiveness, Expenditure and Priority Setting, World Health Organization, Geneva, Switzerland
}

Cost effectiveness analyses of the many interventions (primary prevention, screening or treatment) for reducing the burden of colorectal cancer have usually been restricted to developed country settings and with often considerable variation in the analytical methods used. This limits the value of the existing literature to inform colorectal cancer control policies in low to middleincome country settings. Assessment of costs and effects of different strategies can help guide decisions on the allocation of resources across interventions, as well as between interventions for colorectal cancer and interventions for other conditions or risk factors.

This research presents estimates on the costs and effects of various combinations of available intervention strategies for colorectal cancer across regions using standardised methods, data sources and tools [2-10] that 
have been developed by the WHO-CHOICE (CHOosing Interventions that are Cost Effective) program. The results should help answer policy questions such as whether and what type of screening programmes should be added in populations with a high level of access to treatment, or, in developing countries, whether to put scarce resources into screening or into expanding levels of treatment coverage. In addition, the study will facilitate the prioritisation process by allowing comparisons to be made, using similar methodologies, with interventions (whether, primary prevention, screening or treatment) for cardiovascular [11] and other diseases [12].

\section{Methods}

\section{WHO-CHOICE framework}

WHO-CHOICE comprises sectoral, population-level cost-effectiveness analyses based on a generalized costeffectiveness analysis framework [6]. Generalized costeffectiveness analysis is characterized by the assessment of costs and effects against a reference scenario defined as the absence of all current interventions against the disease or risk factor (the "null scenario"). This approach facilitates [13] the comparison of cost-effectiveness findings across competing interventions [14].

Costs and effects of key interventions for colorectal cancer were modeled at the population level in 14 WHO regions [15].

Basically there are two stages to the calculations:-

i) We first constructed a model that predicted intervention-specific decreases in incidence and case fatality rates.

ii) The data from the first model was then combined with regional specific demographic and cost data and run over a time period of one hundred years in order to predict regional intervention specific outcomes in terms of costs and DALYs saved.

\section{Choice of interventions}

The interventions analyzed are listed in Table 1 represent protocols that are either recommended [16] or used in some countries [17] or combinations there of. The reference strategy in keeping with the methodology of generalized cost-effectiveness analysis is the null consisting of no intervention or treatment.

These can be grouped into the following categories:-

Repeated Screening (followed by removal of polyps or potentially cancerous lesions)

i) Five interventions represent longitudinal screening programs based on current consensus recommendations [16]. These interventions (Annual and Biannual FOBT, Sigmoidoscopy every 5 years, Colonoscopy every 10 years and Annual FOBT with Sigmoidoscopy every 5 years) are analysed first in a scenario where no treatment (radiotherapy, surgery or chemotherapy) for cancers is available. Individuals screened positives are assumed to have follow-up colonoscopy with the removal of any detected polyps or lesions.

One-off Screening (with polyp and lesion removal)

ii) Four additional interventions (FOBT, Sigmoidoscopy, Colonoscopy and Annual FOBT with Sigmoidoscopy combined) represent a one-off screening program (with polyp and lesion removal) for persons aged 50 years, akin to the sigmoidoscopy program recently introduced in France.

\section{Treatment}

iii) Treatment interventions include combinations of surgery, radiotherapy and chemotherapy, consistent with current practice in developed countries.

\section{Repeated Screening (with polyp and lesion removal) and treatment}

iv) A combination intervention consisting of each of the five repeated screening programs in a scenario where treatment is available.

\section{One-Off Screening (with polyp and lesion removal) and treatment}

v) A combination intervention consisting of each of the four one-off screening programs at age 50 in a scenario where treatment is available.

\section{Prevention}

vi) Increasing fruit and vegetable consumption by means of mass media campaigns. The cost-effectiveness of this intervention is likely to be underestimated in this analysis as the likely benefits of decreases in other diseases, such as cardiovascular disease and strokes, was beyond this analysis's scope [17].

\section{Other interventions of uncertain efficacy}

vii) The final two interventions are annual Digital Rectal Exams (DRE) with and without medical treatment. These were included because of its "low-technological" approach for possible use in developing countries, despite the fact that evidence for this intervention vis-àvis colorectal cancer is based on non-significant results from a lone case-control [18]. Despite not being recommended in most developed countries, results have been presented for comparative completeness. While we included benefits of DRE of reducing colorectal cancer, we did not include any possible benefits resulting from reducing prostate cancer.

\section{Interventions not included}

Double contrast barium enema was not analyzed due to the lack of evidence of reductions in incidence or mortality [19-22]. Furthermore, barium screening has low sensitivity for diagnosing symptomatic patients [19] and polyps [23] and hence limited applicability to population screening. Finally, compliance is likely to be low due to the perceived unpleasant nature of the test [22]. 
Table 1 Estimated Effects of Interventions (based on model of AMRA region) and assumed Compliance data that were inputted into POPMOD model

\begin{tabular}{|c|c|c|c|c|}
\hline Intervention & Description & $\begin{array}{c}\text { Decrease } \\
\text { in Incidence }\end{array}$ & $\begin{array}{c}\text { Decrease } \\
\text { in } \\
\text { Case-Fatality Rate }\end{array}$ & Compliance \\
\hline FOB1 & Annual Fecal Occult Blood Tests ${ }^{a}$ & $35.0 \%$ & $0 \%$ & $56.8 \%$ \\
\hline FOB2 & Biannual Fecal Occult Blood Tests ${ }^{a}$ & $21.9 \%$ & $0 \%$ & $61.8 \%$ \\
\hline SIG5 & Sigmoidoscopy every 5 years $[1]^{a}$ & $38.9 \%$ & $0 \%$ & $45.0 \%$ \\
\hline COL10 & Colonoscopy every 10 years $^{\mathrm{a}}$ & $52.6 \%$ & $0 \%$ & $45.0 \%$ \\
\hline FOB1SIG5 & Annual FOBT, SIG every 5 years $^{a}$ & $51.5 \%$ & $0 \%$ & $45.0 \%$ \\
\hline FOB50 & FOBT at age $50^{a}$ & $2.6 \%$ & $0 \%$ & $71.8 \%$ \\
\hline SIG50 & Sigmoidoscopy at age $50^{a}$ & $11.8 \%$ & $0 \%$ & $55.0 \%$ \\
\hline COL50 & Colonoscopy at age $50^{\mathrm{a}}$ & $25.9 \%$ & $0 \%$ & $55.0 \%$ \\
\hline FOBSIG50 & FOBT \& SIG at age $50^{a}$ & $13.2 \%$ & $0 \%$ & $55.0 \%$ \\
\hline $\mathrm{RX}$ & Medical Treatment of cancers ${ }^{b}$ & $0 \%$ & $91.9 \%$ & $100 \%$ \\
\hline FOB1RX & Combination of FOB1 \& RX & $35.0 \%$ & $17.9 \%^{\mathrm{c}}$ & $56.8 \%$ \\
\hline FOB2RX & Combination of FOB2 \& RX & $21.9 \%$ & $12.9 \%^{\mathrm{C}}$ & $61.8 \%$ \\
\hline SIG5RX & Combination of SIG5 \& RX & $38.9 \%$ & $3.4 \%^{c}$ & $45.0 \%$ \\
\hline COL10RX & Combination of COL10 \& RX & $52.6 \%$ & $3.9 \%^{c}$ & $45.0 \%$ \\
\hline FOB1SIG5RX & Combination of FOB1SIG5 \& RX & $51.5 \%$ & $18.3 \%^{\mathrm{c}}$ & $45.0 \%$ \\
\hline FOB50RX & Combination of FOB50 \& RX & $2.6 \%$ & $0.5 \%^{c}$ & $71.8 \%$ \\
\hline SIG50RX & Combination of SIG50\& RX & $11.8 \%$ & $0.3 \%^{c}$ & $55.0 \%$ \\
\hline COL50RX & Combination of COL50\& RX & $25.9 \%$ & $0.4 \%^{c}$ & $55.0 \%$ \\
\hline FOBSIG50RX & Combination of FOBSIG50 \& RX & $13.2 \%$ & $0.5 \%^{\mathrm{c}}$ & $55.0 \%$ \\
\hline FVCAMP & Fruit \& Vegetables campaign & d) & $0 \%$ & - \\
\hline FVCAMPRX & Combination of FVCAMP \& RX & d) & $0 \%^{c}$ & - \\
\hline DRE1 & Digital Rectal Exam annually ${ }^{a}$ & $17.6 \%$ & $0 \%$ & $50 \%$ \\
\hline DRE1RX & Combination of DRE1 \& RX & $17.6 \%$ & $1.8 \%^{\mathrm{C}}$ & $50 \%$ \\
\hline
\end{tabular}

Notes:

Subscripts 1,2,5,10 (eg: SIG5] in the intervention column denote the frequency of screening in years.

Subscript 50, denotes a one off intervention at age 50 .

$\mathrm{RX}$ denotes the availabily of treatments for cancers in addition to the intervention program.

Efficacy varied slightly between regions due to demographic differences.

Efficacy considered on an age-sex specific basis.

a) Denotes colonoscopy performed on all positive tests, with subsequent removal of lesions or polyps if discovered.

b) Including surgical, radiotherapy and chemotherapy.

c) In excess of decrease in CFR caused by treatment.

d) Varies by region

Despite the availability of data on consumption and price elasticity $[24,25]$, price subsidies to increase fruit and vegetable consumption were not analyzed due to theoretical difficulties in calculating intervention costs in economic terms (since subsidies are transfer payments from the government to consumers). A further complication is a possible increase in red meat consumption, itself a potential risk factor for colorectal cancer [26,27], due to income effects.

Other preventive interventions like mass media campaigns to increase physical activity $[28,29]$ and reduce body mass index were excluded because of insufficient data on the large-scale efficacy of such campaigns. The effects of changing transport modes (e.g. increasing rail and bike travel) and of urban planning (eg. decreasing "sprawl") on physical activity were also excluded due to lack of time-series data [30,31].

Reducing tobacco use was not considered because available evidence is insufficient to show a causal link with colorectal cancer [32]. Lack of data on efficacy was the primary reason for excluding palliative care for latestage cancers.

Aspirin [33] or Folic Acid [34] were not considered as potential interventions because evidence for their efficacy is only based on case-control and cohort studies. This level of evidence does not meet the WHO-CHOICE requirement of evidence from randomized controlled trials in order to evaluate pharmacological interventions. 


\section{Estimates of efficacy of interventions (Table 1]}

To date, there have only been four randomized trials on Fecal Occult Blood Tests [35] (FOBT), the longest trial based on 18 years of follow up [36] reported decreases in incidence of colorectal cancer of $20 \%$ and $17 \%$ for annual and biennial screening respectively. Since these randomized trials reported results of guaiac FOBT as opposed to immunological tests, all the results in this paper relate to guaiac FOBT testing. Results from current randomized sigmoidoscopy trials (a once-per-lifetime study performed in the UK and a penta-annual USA study that included additional annual FOBT testing), are not yet published. To date, there have been no randomized trials of colonoscopy.

Evidence is not available from randomized trials of the efficacy of various screening interventions (except for FOBT). Therefore researchers often rely on modeling techniques in order to estimate the effects of screening for colorectal cancer. As a result of variations in quality, specification and parameter values, model results vary considerably (as detailed in the opening paragraph of the discussion).

Since no single model can be regarded as a "gold-standard", we constructed our ownmodel using a spreadsheet to estimate the effects of various screening interventions aimed at the general population aged 50 to 80 years old. The model allowed for examining the effects of varying the frequency of screening and age at time of screening. This model was based on demographic data from the WHO AmrA region (i.e. Canada, Cuba and the USA) and colorectal cancer incidence rates from the SEER registry in the USA for the period 1995-2000 [37]. Age-specific polyp incidence was estimated from prevalence data based on the weighted average polyp prevalence from studies on populations in the USA [38-46].

Age-specific rates of cancers originating in adenomateous polyps were calculated under the consensus-based assumption that $70 \%$ of cancers originated in adenomateous polyps $[47,48]$ and that the average waiting time for development of cancer was ten years [22,47-50] (assumed normally distributed with a standard deviation of four years). The incidence of polyps was matched with future incidence of cancers originating from polyps in order to calculate the conversion rates from polyps to cancers, taking into account intervening mortality. Thus a proportion of polyps at each stage were assumed to be potentially carcinogenic and placed in a waiting state from which they were allowed to become malignant at a constant rate. Cancers were assumed to wait for two years in stage A and for one year in each of the three subsequent stages, if left untreated $[47,51,52]$.

Using stage-specific fatality rates, the expected number of cancer cases and cancer fatality were estimated under a baseline scenario of no screening. Data on sensitivity and specificity of screening [47] was used to estimate the number of persons undergoing follow-up colonoscopy (assuming $100 \%$ compliance after a positive test) and the number undergoing polypectomy during the colonoscopy. For each intervention, based on the sensitivity, specificity and frequency of screening, the model estimated the number of polyps that would progress to cancers.

Despite their being some misgivings [53], our model was based on the mainstream accepted wisdom [54] that screening enables detection and removal of potentially cancerous polyps, thereby reducing the incidence of colorectal cancer even when cancer treatment was not available.

When medical treatment is available, screening enables detection of cancers at an earlier less-severe stage, thus reducing case-fatality rates (CFR). It was assumed that persons screened positive in areas which lack availability of treatment will only benefit via reduction in incidence (via polyp removal) and not via decreases in case-fatality rate due to the lack of treatment. We assumed that there would not be a change to more frequent protocols in persons who had a polyp removed.

These modeled intervention-specific estimates of CFR reductions, together with estimates of incidence reductions (Table 1) form the main inputs into a population based model described later on in this article.

The effectiveness of the fruit and vegetable campaign was calculated from the results of the campaign in Victoria, Australia [55], which achieved an increased intake of around $12.4 \%$ by weight in fruit and vegetable consumption. Assuming each $80 \mathrm{mg}$ increase in average regional daily consumption results in a $1 \%$ decrease [95\% CI, $-2 \%,+3 \%)$ in colorectal cancer risk [24], this translates into risk reductions ranging from $0.34 \%$ in South America to $0.78 \%$ in Western Europe.

\section{Validation of model}

For a specific validation of the model, the estimated decrease in incidence due to annual FOBT screening was found to be almost equal to benchmark data from 18 -year follow up of the randomized controlled trial after adjustment for the period during the trial when screening was temporarily halted, as well as adjustment for compliance [36].

For general validity, across the various interventions, the estimated decreases in incidence and fatality over and above that due to treatment (Table 1) fell within the 25 th and $75^{\text {th }}$ percentile range of the many modeled studies $[47,49,56-73]$.

\section{Compliancy}

The effects of each intervention were modified by their specific adherence or compliancy. The estimated 
magnitude of compliancy that was calibrated into the model was based on reported compliancy and assumptions as follows:-

Information on compliance with FOBT screening protocols were obtained from a demonstration project for annual screening [74] (i.e. 56.8\%); biannual screening was assumed to result in 5\% higher compliance. Compliance with screening by colonoscopy every 10 years, as well as annual FOTB combined with sigmoidoscopy every 5 years, was assumed to be the same as that found for a pre-intervention pilot study for sigmoidoscopy [75] (i.e. $45 \%$ ), the greater invasiveness and more intensive preparations required for colonoscopy were assumed to be balanced by the longer interval required between screenings. Estimates of compliance for one-off screening at age 50 years was assumed to be $10 \%$ higher than that for repeated screening starting at age 50 and finishing at age 80 (Table 1). Due to the difficulties of estimating compliancy over a 30 year period, involving between 4 and 30 screening visits, all estimates of compliancy used in the model should be viewed as rough approximations. Intervention effectiveness was adjusted for the compliance assuming a target coverage rate of $100 \%$ for all regions.

\section{Definition of the null scenario}

There is little direct evidence regarding the natural history of colorectal cancer in the absence of treatment. One small study in the USA found a $4.2 \%$ ten-year survival rate in persons who refused treatment $(n=24)$, for unstated reasons [76].

Our estimates of regional cancer incidence, mortality and remission rates were based on aggregated country data from the WHO. In countries where mortality data was incompletely reported, the WHO proxied estimates of cancer mortality by estimating survival data based on a function of the level of economic development of the specific countries $[77,78]$.

AfrE and AmrA have low and high remission rates as a result of their treatment coverage rates (in the 30-69 age group) being respectively low [6.7\%) and high [95\%$100 \%)$. Linear extrapolations were made to this data in order to estimate age-and-sex-specific remission (and hence ten-year fatality) rates in the absence of treatment (ie: $0 \%$ treated).

Ten-year remission and fatality rates were converted to annual hazards according to the following formulas [79]:

$$
\frac{\ln [1-\% \text { remitting })}{10 \text { years }} \text { and } \frac{\ln [1-\% \text { dying from colorectal cancer })}{10 \text { years }}
$$

Similarly, based on data from the AmrA region, where treatment coverage ranged from $90 \%-100 \%$, linear extrapolations were made to estimate age-and-sex-specific ten-year fatality and remission rates assuming complete treatment of all colorectal cancers. The resutling estimates of overall remission and fatality rates were used for the various analysed treatment scenarios.

In 2000, the AmrA region of WHO was the only region globally where any significant level of population screening for colorectal cancer was being carried out (personal communication, Wendy Atkin, UK Colorectal Cancer Unit, St Marks Hospital, Middlesex). Based on modeled estimates of the effectiveness of screening, the observed incidence of colorectal cancer in AmrA was adjusted to reflect the higher incidence that would have occurred if a small percentage of the population had not been screened [80].

\section{Population Model (PopMod) for colorectal cancer}

Based on the estimates obtained from the epidemiological model, population-level intervention effectiveness was estimated using a population state transition model [78] simulating the regional population demography (Additional file 1) and the effects of the disease in question (Fig. 1).

Health state valuations (HSV), based on data used by the WHO to estimate the Global Burden of Disease (GBD) (Personal Communication K. Shibuya, WHO), were specified (on a 0-1 scale, where 1 equals full health) for time spent in susceptible or diseases states $(0.8$ for diagnosis and treatment, 0.8 for watchful waiting whether in a treated or not treated person, 0.25 for metastasis and 0.19 for terminal stage). In keeping with the GBD methodology, no additional disability weight was ascribed to a case after a person had survived five years unless they possessed a permanent colostomy, which was ascribed a HSV of 0.79 as a result of perforation of the colon occurring in $0.129 \%$ [48,56-59,64,66,70,71] of colonoscopies and an assumed $9 \%$ of all colorectal cancer related surgical procedures.

Based on the categories "treated and survived", "treated and died", "not treated and died", "died from background causes", the weighted average age-and-sexspecific health state valuation were calculated for the null scenario, the complete treatment scenario and the scenarios of screening with treatment.

For each scenario, the initial population data inputted into the model, was projected forward for a period of 100 years. The difference in the total number of healthy years between each intervention simulation and the baseline (null) scenario was the estimate of populationlevel health gain due to the intervention. In keeping with the standardized WHO-CHOICE methodology DALYs averted were calculated and are discounted at a rate of 3\% per annum and are age-weighted by weighting a year of healthy life lived at younger and older ages lower than a year lived at other ages [81]. 


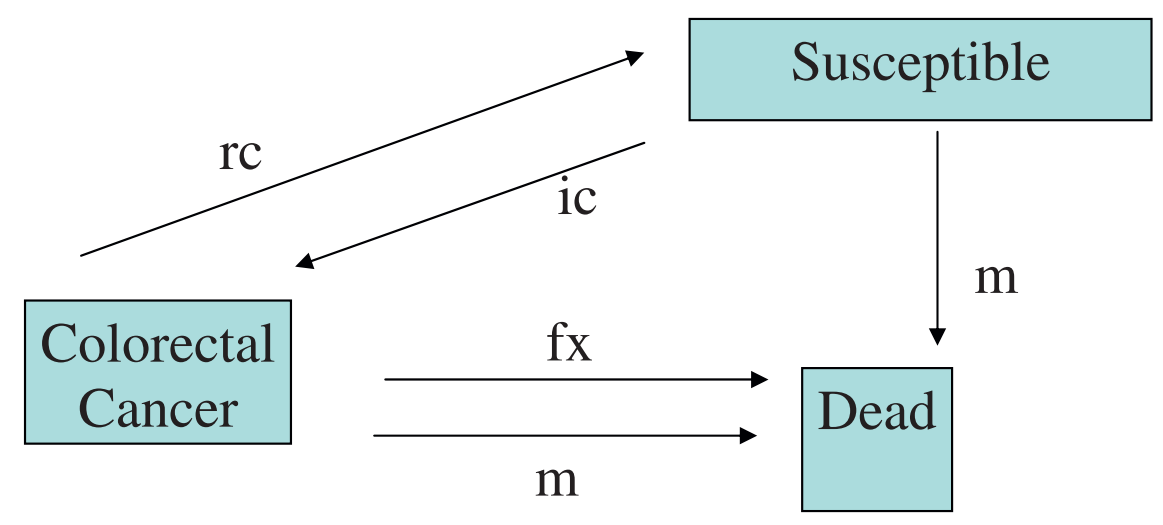

Figure 1 POPMOD model of Colorectal Cancer. ic is colorectal cancer incidence rate, $r c$ is colorectal cancer remission rate, $\mathrm{m}$ is background mortality rate, $\mathrm{fx}$ is colorectal cancer mortality rate.

\section{Costs of Colorectal cancer interventions}

Costs for the 10-year intervention implementation period were discounted at $3 \%$ and expressed in international dollars $(\$ \mathrm{I})$ at year 2000 price levels. An international dollar is a unit of currency with purchasing power equivalent to a US dollar in the USA [11]. Costs in local currency units were converted to international dollars using purchasing-power-parity (PPP) exchange rates. Expressing costs in international dollars facilitates more meaningful comparisons across subregions by adjusting for differences in local relative prices.

For the annual FOBT, program costs (excluding the actual costs of the FOBT), were based on an estimate of around 27 administrative posts (for notification, sending out test kits, results etc.) per 5 million population in each region in addition to a budget for media, office space and other items. Program costs for the other screening interventions and regions were adjusted to reflect the type of intervention (eg: no test kits need to be sent for sigmoidoscopy or colonoscopy), the intervention's relative frequency and the size of the target population. In less developed sub-regions (ie: regions characterized by mortality stratum $\mathrm{D}$ or $\mathrm{E}$ in reference 15 ) it was assumed that in the absence of a postal system, health workers would deliver the FOBT kits by hand and the kits would be returned to laboratories en bloc from the district health centers. In addition, each program had a provision for staff training and national posts for management, monitoring and evaluation based on the British NHS Cancer Screening Programs.

Quantities (manpower time, rooms, drugs, disposable and reusable equipment) for screening tests and treatment procedures were based on the WHO Collaborating Centre for Essential Health Technologies data base. Provision was made for pre-operative work-up tests such as $\mathrm{CT}$ scan and Chest X-rays [82]. If further data was available from published literature we adjusted the manpower time to be in accord with the published literature. For example, recent literature estimated 145.5 and 165.5 minutes average time for a colectomy [83] with and without colostomy respectively, bringing the cost of the operation up to \$I845 and \$I906 in AmrA, including a provision for an assumed $10 \%$ of procedures to be carried out under combined spinal-epidural anaesthesia [84]. Proctectomies were assumed to take 60 minutes longer than colectomies.

Estimates of direct cost per test (excluding programme and training overheads) for the AmrA region of \$I 4, \$I 71 and \$I 190 for FOBT, diagnostic sigmoidoscopy and diagnostic colonoscopy, respectively, were similar to those reported in Holland [65] and Israel [72]. Colonoscopy costs included not only preparation, obtaining consent, procedure and recovery time but also one full hour for pre-screening counseling. Discounted costs of lifetime care for perforated colon were assumed to be around \$I 13,000 [58], consisting of hospitalization, anesthesia, colon suture, electrocardiography, X-ray and initial care costs.

Unit costs of secondary and tertiary hospital in-patient days and out-patient visits were based on an econometric analysis of a multinational dataset of hospital costs [3]. Prices of pharmaceuticals were obtained from international [85] or from British National Health Service prices [86] adjusted to year 2000 price levels. Annual resource use per case on a stage-specific basis (i. e. initial, watchful waiting and terminal) was based on Medicare data from the USA (personal communication, Martin L. Brown, Health Services and Economic Branch, National Cancer Institute, Bethesda MD.). Liver function tests were assumed to be given monthly for one year, CT scans annually for three years, carcino-embrionic antigen tests every 6 months for three years, chest 
$\mathrm{X}$-rays annually for 3 years and follow-up colonoscopies biannually [49].

Average unit costs (see Additional file 2) were multiplied by the number of units of care required by the sub-regional population, to estimate the total annual intervention cost.

\section{Decision rules}

An intervention was termed very cost-effective and costeffective if the cost per DALY was less than the per capita GNP or between 1 and 3 times per capita GNP, respectively. If the cost per DALY was more than three times the GNP per capita, then the intervention was regarded as not cost effective [87]. Sensitivity analyses were performed to generate costs per DALY under scenarios with no age-weighting and without discounting at $3 \%$ per annum.

For each region, graphical plots for each intervention of DALYs gained against costs were made in order to identify the most cost-effective interventions. The lines joining the loci of the most cost-effective points form the "expansion path", which reveals the mix of interventions that would be chosen on cost-effective grounds for any given level of resource availability [5].

\section{Results}

We present the results for three representative regions (Table 2]: AmrA, characterised according to the WHO rubrick [1] by high income (\$I 31,477 GNP per head) and low child and adult mortality, EurC, characterised by low income (\$I 6,916 GNP per head), low child and high adult mortality and AfrE, characterised by very low income (\$I 1,576 GNP per head), high child and very high adult mortality.

AmrA (Canada, United States Of America, Cuba)Two main groups of interventions emerge in the AmrA region (Fig. 2) which are based on the results presented in Table 2.

The first consists of the screening interventions (with surgical removal of polyps) in an environment where treatment (in the form of surgery, radiotherapy and chemotherapy) was not provided. Campaigns to increase fruit and vegetable consumption are close to the expansion path (indicating the lowest costs per DALY for that level of resource usage) despite the omission of benefits from decreases in diseases besides colorectal cancer. However such an intervention only accounted for a small absolute reduction in DALYs. One-off colonoscopy at age 50 falls on the expansion path. However, because of the variability inherent in both the effectiveness (i.e: increase in DALYS saved) and cost estimates, it is unlikely that there are any significant differences in the cost per DALY generated by any of the screening methods, implying no one single method can be thought of as dominant. Interventions in this group are all very cost effective (including the use of the DRE) shown by their falling to the right of the broken-arrow line indicating the points where the cost per DALY are exactly equal to the GDP per capita.

The second group consists of screening interventions with treatment. Interventions in this group cost more and yield more DALYs than interventions in the first (no-treatment) group, although they are still very cost effective. In this treatment scenario, annual FOBT combined with sigmoidoscopy every five years is now indicated by being on the expansion path (Fig. 3), having an incremental cost effectiveness ratio (ICER) well below the GNP per head threshold. Once again due to variations in the estimates, no single intervention combined with treatment can be thought of as being superior to the others.

EurC (Belarus, Estonia, Hungary, Kazakhstan, Latvia, Lithuania, Republic of Moldova, Russian Federation, Ukraine)

Again two main distinct groupings emerge (Fig. 4) which are based on the results presented in Table 2 . However the no-treatment group is less homogeneous than in AmrA. The one off screening interventions at age 50 (colonoscopy, sigmoidoscopy with and without FOBT) were very cost-effective as was sigmoidoscopy every five years and colonoscopy every ten years. The other screening interventions (including the DRE) were just cost-effective, falling between the dotted and dashed lines representing the three and one times the GNP per head thresholds respectively.

All the screening interventions with treatment are very cost effective falling to the right of the dashed line. As more resources become available the expansion path shifts interventions in the current scenario (characterised by medium levels of treatment coverage) to universal treatment, then to sigmoidoscopy at age 50 , colonoscopy at age 50 , to colonoscopy screening every 10 years, gaining the most DALYS when a combined FOBT and sigmoidoscopy programme is complemented by full treatment (Fig. 5).

The ICER of moving along the expansion path showed that all the interventions up to supplying colonoscopies every 10 years to be very cost-effective. However expansion to a combined FOBT and sigmoidoscopy intervention might be considered as just cost effective as its ICER is between one and three times the per capita GNP. Once again, no single intervention combined with treatment dominates.

AfrE (Botswana, Burundi, Central African Republic, Congo, Côte d'Ivoire, Democratic Republic Of The Congo, Eritrea, Ethiopia, Kenya, Lesotho, Malawi, Mozambique, Namibia, Rwanda, South Africa, Swaziland, Uganda, United Republic of Tanzania, Zambia, Zimbabwe) 
Table 2 Average Cost per DALY in relation to the null of interventions to reduce Colorectal Cancer in selected WHO subregions

\begin{tabular}{|c|c|c|c|c|c|c|c|c|c|}
\hline \multirow{3}{*}{ Intervention } & \multicolumn{3}{|c|}{ AFRE } & \multicolumn{3}{|c|}{ AMRA } & \multicolumn{3}{|c|}{ EURC } \\
\hline & COST & DALYS saved & $\begin{array}{r}\text { COST } \\
\text { per } \\
\text { DALY }\end{array}$ & COST & $\begin{array}{l}\text { DALYS } \\
\text { saved }\end{array}$ & $\begin{array}{r}\text { COST } \\
\text { per } \\
\text { DALY }\end{array}$ & COST & $\begin{array}{r}\text { DALYS } \\
\text { saved }\end{array}$ & $\begin{array}{r}\text { COST } \\
\text { per } \\
\text { DALY }\end{array}$ \\
\hline & I\$ (mill) & & I\$ & I\$ (mill) & & I\$ & I\$ (mill) & & I\$ \\
\hline Current Scenario (a) & 116 & 27,546 & 4,206 & 64,937 & $14,135,241$ & 4,594 & 4,677 & $1,801,461$ & 2,596 \\
\hline FOB1 & 4,193 & 98,525 & 42,557 & 11,745 & $1,603,126$ & 7,326 & 5,440 & 548,649 & 9,915 \\
\hline FOB2 & 2,222 & 66,502 & 33,410 & 6,448 & $1,082,872$ & 5,954 & 2,954 & 370,055 & 7,984 \\
\hline SIG5 & 1,407 & 90,077 & 15,620 & 6,807 & $1,463,474$ & 4,651 & 2,716 & 492,378 & 5,516 \\
\hline COL10 & 1,561 & 117,977 & 13,231 & 7,858 & $2,020,645$ & 3,889 & 3,070 & 661,542 & 4,641 \\
\hline FOB1SIG5 & 4,915 & 121,374 & 40,491 & 15,989 & $1,969,383$ & 8,119 & 7,069 & 665,773 & 10,617 \\
\hline FOB50 & 380 & 12,222 & 31,055 & 1,082 & 198,064 & 5,465 & 526 & 59,843 & 8,786 \\
\hline SIG50 & 531 & 41,910 & 12,669 & 2,446 & 679,950 & 3,597 & 984 & 205,514 & 4,786 \\
\hline COL50 & 1,040 & 91,092 & 11,415 & 5,027 & $1,491,646$ & 3,370 & 1,980 & 449,523 & 4,404 \\
\hline FOBSIG50 & 478 & 46,981 & 10,183 & 3,032 & 762,325 & 3,977 & 860 & 230,391 & 3,734 \\
\hline $\mathrm{RX}$ & 1,394 & 837,066 & 1,666 & 73,225 & $14,991,673$ & 4,884 & 12,145 & $4,200,308$ & 2,891 \\
\hline FOB1RX & 5,461 & 912,458 & 5,984 & 77,579 & $16,300,533$ & 4,759 & 16,481 & $4,630,614$ & 3,559 \\
\hline FOB2RX & 3,524 & 890,163 & 3,959 & 74,346 & $15,929,042$ & 4,667 & 14,328 & $4,507,099$ & 3,179 \\
\hline SIG5RX & 2,706 & 896,387 & 3,019 & 75,839 & $15,864,896$ & 4,780 & 14,100 & $4,518,157$ & 3,121 \\
\hline COL10RX & 2,844 & 909,822 & 3,126 & 76,031 & $16,131,444$ & 4,713 & 14,301 & $4,604,861$ & 3,106 \\
\hline FOB1SIG5RX & 5,110 & 922,577 & 5,539 & 74,917 & $16,382,245$ & 4,573 & 15,584 & $4,672,483$ & 3,335 \\
\hline FOB50RX & 1,758 & 850,239 & 2,067 & 74,130 & $15,200,680$ & 4,877 & 12,633 & $4,275,966$ & 2,954 \\
\hline SIG50RX & 1,897 & 867,915 & 2,185 & 74,793 & $15,433,538$ & 4,846 & 12,975 & $4,357,438$ & 2,978 \\
\hline COL50RX & 2,377 & 899,415 & 2,643 & 76,236 & $15,881,346$ & 4,800 & 13,780 & $4,509,360$ & 3,056 \\
\hline FOBSIG50RX & 2,188 & 871,888 & 2,509 & 75,660 & $15,494,325$ & 4,883 & 14,712 & $4,377,287$ & 3,361 \\
\hline FVCAMP & 275 & 7,618 & 36,074 & 366 & 84,085 & 4,354 & 360 & 17,804 & 20,222 \\
\hline FVCAMPRX & 1,681 & 842,102 & 1,996 & 73,476 & $15,037,102$ & 4,886 & 12,513 & $4,210,885$ & 2,972 \\
\hline DRE1 & 818 & 9,438 & 86,676 & 2,370 & 153,861 & 15,401 & 1,008 & 52,939 & 19,038 \\
\hline DRE1RX & 2,421 & 846,382 & 2,861 & 75,207 & $15,145,147$ & 4,966 & 13,299 & $4,259,810$ & 3,122 \\
\hline Cost-effective threshold & & & 4,728 & & & 94,431 & & & 20,748 \\
\hline Very cost-effective threshold & & & 1,576 & & & 31,477 & & & 6,916 \\
\hline
\end{tabular}

(Discounted at 3\% per annum \& Age-Weighted).

Note: Interventions that fall on expansion path are in bold type.

(a) The current scenario represents the interventions which are currently being provided in the sub-regions. This differs from the reference strategy, the null, where no intervention or treatment is provided.

As a result of cost differentials associated with programme implementation, there is a wide range of costs between screening programmes without treatment (Fig. 6) which are based on the results presented in Table 2 . All of the screening interventions (in the no treatment scenario) were found to be not cost effective (ie: they fall to the left of the dotted arrowed line) due primarily to the lower incidence of the disease in the region.

Universal treatment, (ie: 100\% treatment scenario), colonoscopy at age 50 (with polyp removal), colonoscopy every 10 years and sigmoidoscopy every five years combined with annual FOBT with treatment appear on the expansion path, only the first three being cost-effective (ie: falling between the dotted and dashed lines)
(Fig. 7). However, using the yardstick that any intervention whose ICER is in excess of three times the per capita GNP is not cost effective, then adding any of the screening programmes to treatment will not be considered as being cost effective. Screening persons aged under 50 years old yielded less favourable cost-effectiveness ratios than commencing screening at age 50 years.

\section{Sensitivity analysis}

Applying age weights to health effects is not without controversy [79]. Removing age weighting results in an overall decrease in the cost per DALY of interventions (Additional file 3). In AmrA, Colonoscopy every 10 years (with polyp removal) joins the expansion path, in 

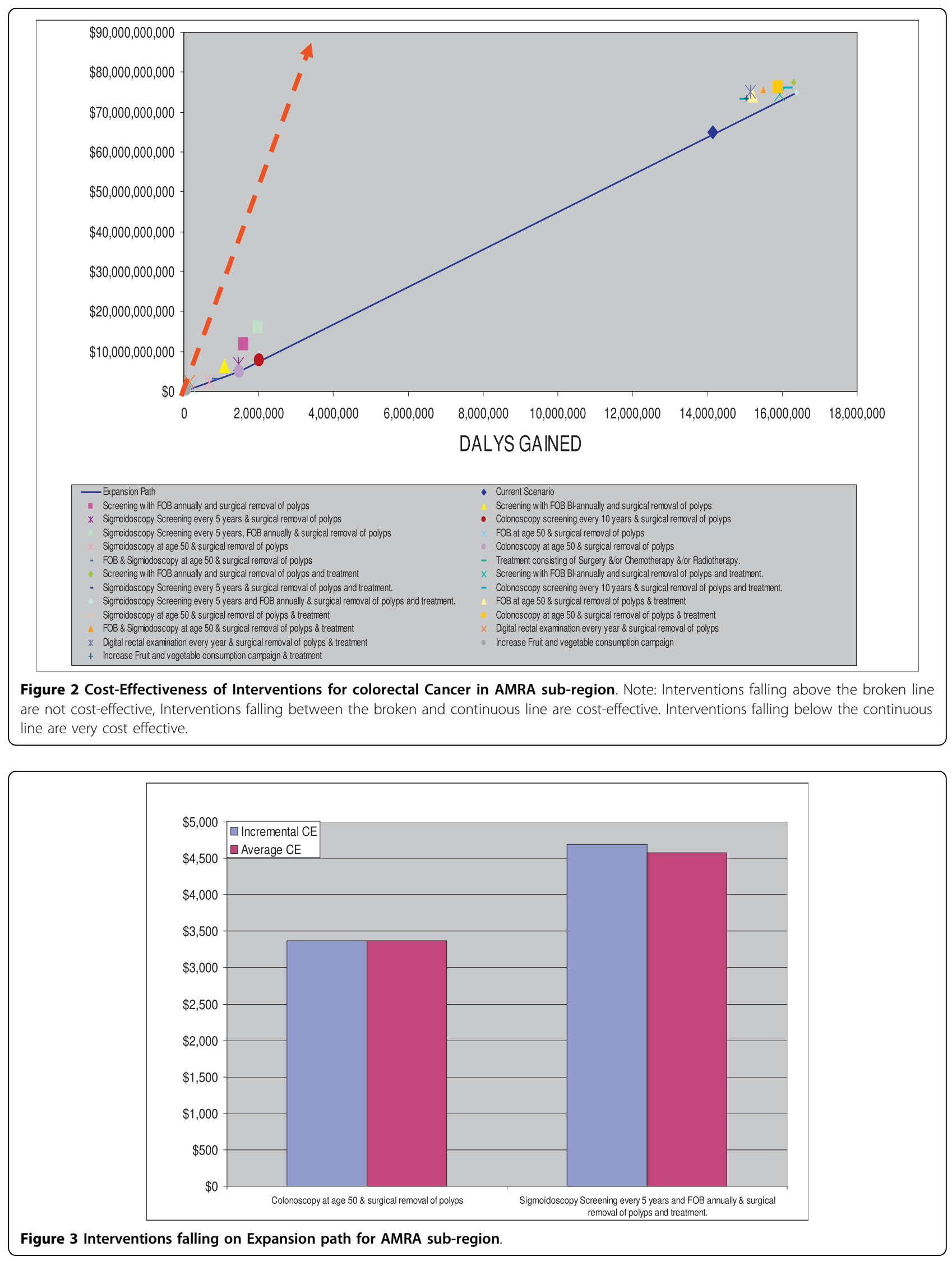

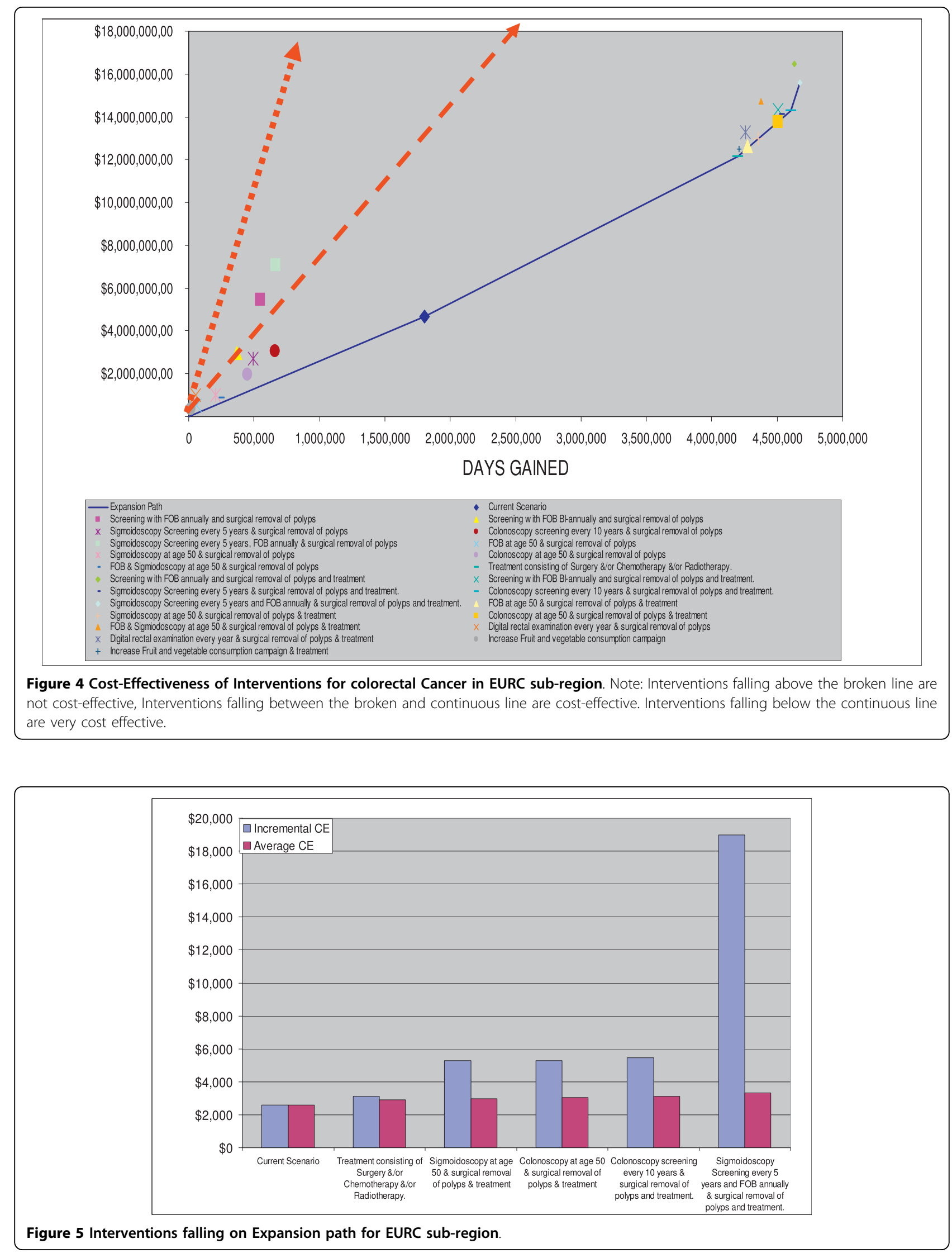


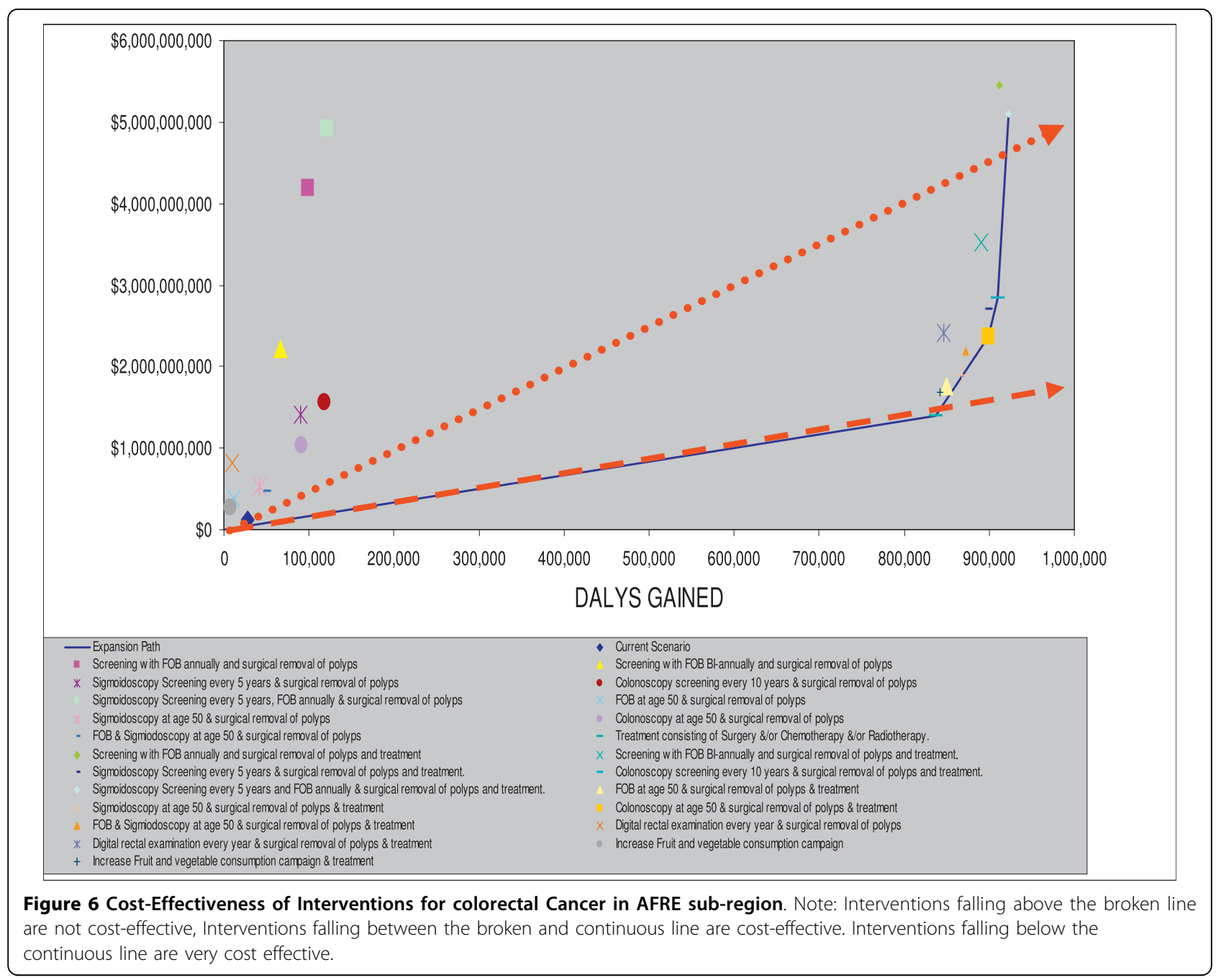

EurC annual FOB with sigmoidoscopy every 5 years (with polyp removal and treatment) joins the expansion path. For AfrE, sigmoidoscopy at age 50 (with polyp removal and treatment) joins the expansion path. The removal of age-weighting means that treating everybody becomes very cost-effective, falling below the GNP per capita threshold.

When both discounting and age-weighting are removed (Additional file 4), costs per DALY fall still further. The expansion path of AmrA consists of colonoscopy at age 50, colonoscopy every 10 years, and sigmoidoscopy every five years combined with annual FOBT (with polyp removal and treatment). In EurC the expansion path consists of treatment only, colonoscopy every 10 years with treatment and sigmoidoscopy every five years combined with annual FOBT with treatment. In AFRE, sigmoidoscopy at age 50 with and without annual FOBT joins universal treatment as being very cost-effective.

\section{Discussion}

Cost-effectiveness estimates for developed countries (mainly USA and countries in Europe) have reported a wide range of incremental costs per life year for the colorectal cancer interventions examined in this, over and above that of treatment alone. Baseline costs per life year (in USD at 2000 price levels) relative to a no screening strategy for both the one-off and repetitive screening vary considerably. Seven studies reported costs per life year of $\$ 20,000$ or more [49,58-60,69-71], eight reported in the range $\$ 10,000-\$ 19,999$ $[47,48,56-59,62,70]$, three between $\$ 5,000-\$ 9,999$ $[55,57,58]$ and three between $\$ 0-\$ 4999[56,64,88]$. Some models even indicated incremental cost-savings (alongside effectiveness gains), both for one-off [72] and repeated screening interventions [56,72].

Such wide ranges in the cost-utility ratio and the subsequent lack of dominance of any one screening mode (reflected by different rankings between the screening 


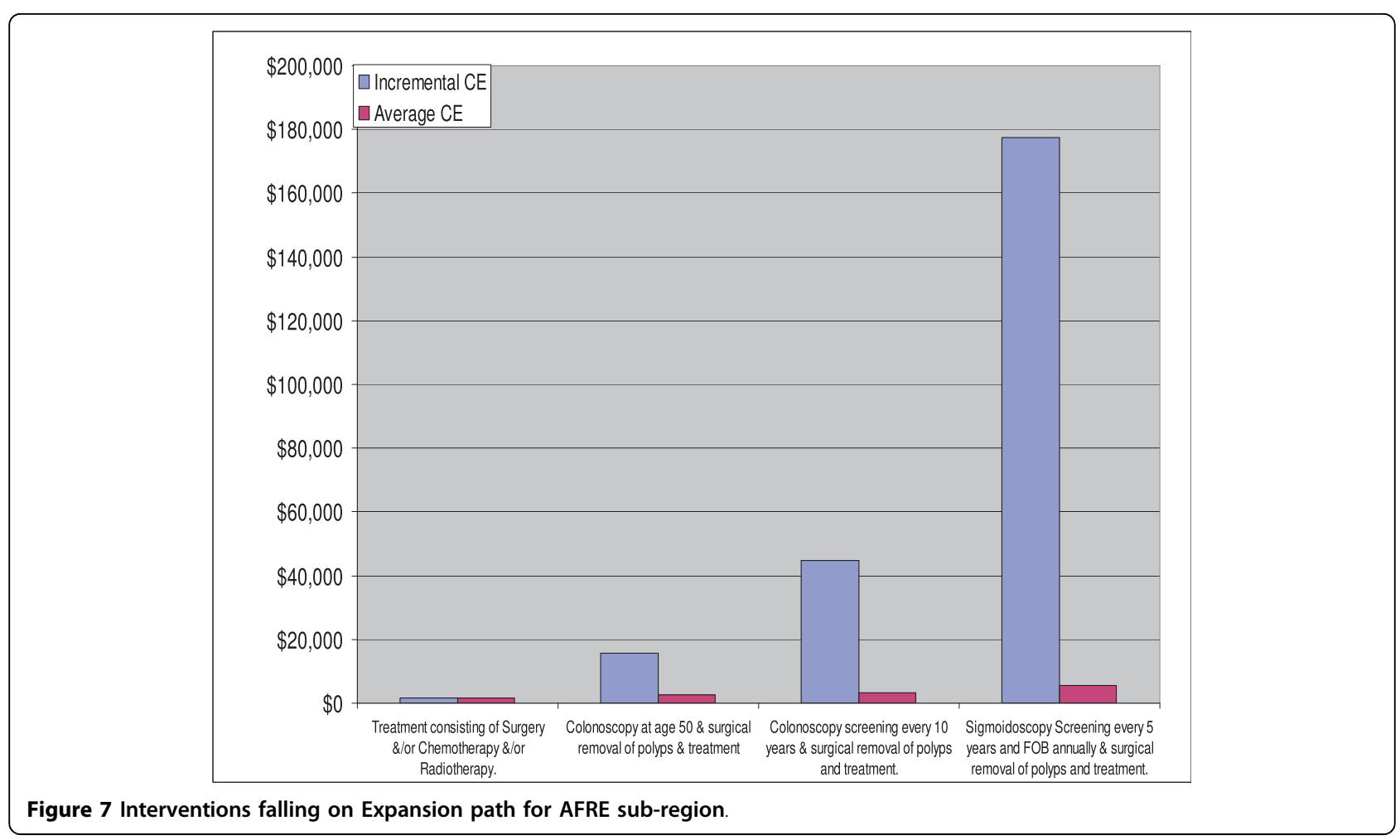

methods) are a consequence of the heterogeneous nature of the model specifications (on the effectiveness side), variations in the duration of operation of screening programmes and wide variations in the estimates of the interventions unit costs. These ranged considerably, with sigmoidoscopy costing between six [69] to 27 times [70] that of FOBT, colonoscopy costing between 10 [72] to 100 times that of FOBT $[57,66]$. Our estimates showed sigmoidoscopy and colonoscopy costs to be between 18 and 48 times that of the basic FOBT test. Additional research is clearly needed on estimating screening programme costs as these considerably affect the cost per DALY outcomes, especially in developing countries.

Our epidemiological model was simpler than most of published models and lacked refinements such as taking into account the distribution of multiple polyps and biphasic polyp dwelling times [68]. In addition, our model did not include provision for more frequent screening of persons identified as having a polyp or with a familial history of CRC.

While our model was based on regional specific age and gender distributions, information on age-specific polyp incidence distribution was based only on available USA data. If a developing country's relative distribution of polyp incidence is skewed to a younger age than the USA, then this would mean that the screening programme would have a lower efficacy (unless screening ages were adjusted) and so our cost-effectiveness ratios are likely to be upwardly biased. On the other hand, our somewhat optimistic compliancy assumption that all persons screened positive on FOBT or Sigmoidoscopy would receive a subsequent colonoscopy served to downwardly bias the presented cost per DAYS, as some cases are likely to be lost to follow-up in practice.

Our estimated cost-effectiveness ratios for the incremental addition of various screening programmes to treatment (for comparability with the literature, discounted at $3 \%$ but not age-weighted; see Additional file 2 ) in AmrA of $\$ 800-\$ 2,200$ per DALY (for screening from age 50 to 80 ) and $\$ 2,400-\$ 3,500$ (for one-off interventions) fell towards the lower end of the wide spectrum of results presented in the opening paragraph of this discussion. This could be attributed to a variety of causes, such as the use of economic costs as opposed to charges or prices for procedures and the longer duration (relative to much of the literature) of the time-horizon used to evaluate our interventions. Inclusion of morbidity gains in our denominator reduced still further our ratios, although this was somewhat counterbalanced by our use of healthy life years in the denominator (as opposed to life years as reported in most of the literature).

In general the following policy recommendations could be inferred from our results. In subregions characterised by high income, low mortality and high 
existing treatment coverage (eg: AmrA subregion), both the incremental (ie: the additional cost per DALY of adding a screening programme to the existing treatment provision) and general (ie: compared to the null) costeffectiveness results point to the very cost-effective nature of the screening intervention, although no particular specific intervention is indicated as being dominant.

In subregions characterised by low income, low mortality with existing treatment coverage around 50\% (eg: EurC subregion), expanding treatment with or without combining it with screening programmes appears to be cost-effective or very cost-effective. Abandoning treatment in favour of funding screening programmes that would operate in a no treatment scenario would not be a cost-effective measure.

In subregions which have low income, low mortality and low treatment levels (eg; AfrE subregion), the best strategy is to provide resources to treat persons with colorectal cancer as opposed to providing a screening programme.

Use of the DRE alone was very cost-effective in the AmrA subregion and cost-effective in EurC. However it has low efficacy and provides a low level of absolute DALY gains. Despite its low technological approach, DRE is not cost-effective in the low incidence AfrE subregion. However, the low cost simple DRE (both with and without follow-up diagnostic colonoscopy), suffers from a lack of direct evidence that the exam reduces mortality from colorectal cancer, our modelled efficacy being based on a single no-significant result $(\mathrm{OR}=0.96$, 95\% CI 0.56-1.70) from a case control study from northern California [18]. Sensitivity is low, as fewer than $10 \%$ of colorectal cancer causing polyps are within reach of the examining finger. There is therefore no solid basis for recommending this method as a stand alone screening intervention for colorectal cancer. Moreover, a comprehensive assessment of this intervention should include its effect on reducing mortality from prostate cancer.

Like the digital rectal examination, the introduction of a fruit and vegetable campaign gains fewer DALYS then any of the screening interventions. Such a campaign was however found to be very cost effective in AmrA even without the inclusion of additional benefits resulting from decreases in other diseases. The fruit and vegetable campaign was marginally cost-effective in EurC, but was not cost-effective at all in AfrE. However, the external validity of applying the effectiveness results from one health promotion campaign in Australia [55] to other regions of the world can be questioned.

The $20 \%$ price subsidy will actually be less effective than health promotion in increasing fruit and vegetable consumption, and hence in reducing colorectal cancer. Estimating the economic cost of such an intervention is beyond the scope of this paper. Moreover, an evaluation of such an intervention requires the effectiveness benefits of reductions in heart disease, stroke and other cancers to be included. The cost per DALY, however, might be underestimated since the income freed up by the food subsidy might result in increased consumption of red meat, which could well be a risk factor for colorectal cancer $[26,27]$.

Our use of a single measure of relative risk reduction for each age and gender specific intervention simplifies the reality, where the risk reduction and subsequent cost-effectiveness ratio can differ depending on the socio-economic context of the screening subgroups [88]. One could also argue that present models on colorectal cancer screening are inadequate for aiding public health decision-making because the efficacy evidence is too preliminary for any screening modality other than FOBT [89]. Lack of such randomized controlled trial evidence precluded an evaluation of immunological FOBT testing, which is likely to yield lower costs per QALY than guaiac-based tests [61], due to the higher sensitivity of immunological FOBT to detect colorectal neoplasms [90-92] outweighing increased unit costs. Our analysis also did not consider the options of targeting screening to high-risk populations which despite reducing the overall DALY gains may well increase the cost-effectiveness of the interventions [51].

The CEAs presented represent first order point estimates of various interventions. When allowance is made for variations of the estimates by sensitivity analysis then it appears there is no clear discernable difference in terms of cost-effectiveness between the major screening options. Perhaps another key factor in deciding what option or mix of options to adopt, would be those interventions which have the highest expected attainable coverage rates. Adoption of screening policies between the ages of 50 and 80 will only eradicate a small portion (between 14\%-24\%) of the existing colorectal cancer burden, since the application of the compliancy rate to the intervention efficacy, even in the case of colonoscopy every 10 years will only result in a $24.1 \%$ reduction in incidence. One-off screening policies will reduce an even lower percentage of the total disease burden.

The cost-effectiveness ratios are insensitive to changes in compliancy, particularly in scenarios that include access to treatment and where programme operational overheads are low. Basically, the increases or decreases in programme efficacy resulting from changes in compliancy are somewhat counterbalanced (except for the programme cost overheads) by decreases or increases in costs.

The cost-effectiveness ratios are also biased upwards (or downwards) to the extent that transport costs and costs of work lost due to treatment exceed (or are 
exceeded by) the transport costs and costs of work lost due to screening $[93,94]$.

Decisions to adopt interventions are usually made by health services and governments at the country level. Although the model used in this analysis is based on regions, the parameters defining the model can be adjusted to country level.

\section{Additional file 1: Selected Variables by Region.}

Additional file 2: Unit Cost (\$ International) by Selected Regions.

Additional file 3: Average Cost per DALY in relation to the null of interventions to reduce Colorectal Cancer in selected WHO subregions.

Additional file 4: Average Cost per DALY in relation to the null of interventions to reduce Colorectal Cancer in selected WHO subregions.

\section{Abbreviations}

CEA: Cost Effectiveness Analysis; CFR: Case Fatality Rate; CHOICE: Choosing Interventions that are Cost-Effective; DALY: Disability Adjusted Life Year; DRE: Digital Rectal Exams; EIP: Evidence and Information in policy; FOBT: Fecal Occult Blood Test; GBD: Global Burden of Disease; GCEA: Generalized Cost Effectiveness Analysis; GNP: Gross National Product; HSV: Health Status Valuation; ICER: Incremental Cost Effectiveness Ratio; Ln: Natural Logarithm; POPMOD: A state transitional population model; PPP: Purchasing Power Parity; HO: World Health Organization.

\section{Acknowledgements}

The authors wish to thank the following for contributing data and/or knowledge to the study. Taghreed Adam (WHO/EIP), Wendy Atkin, UK Colorectal Cancer Unit, Middlesex), Melanie Bertram (WHO/EIP), Martin L. Brown (NIH, Bethesda MD), Peter Heinmann (Essential Health Technologies Medical Research Council, Cape Town). Cedric Mahe (IARC, Lyon), Julia Patnick (NHS Screening Programme, Sheffield), Arnaud Roth (Geneva University Hospital), Kenji Shibuya (WHO/EIP), RJC Steele (Ninewells Hospital and Medical School, Dundee).

\section{Author details}

${ }^{1}$ Costs, Effectiveness, Expenditure and Priority Setting, World Health Organization, Geneva, Switzerland. ${ }^{2}$ Chronic Diseases Prevention and Management, World Health Organization, Geneva, Switzerland.

\section{Authors' contributions}

GG collected data, designed, calculated and wrote up the study. SL provided technical assistance with the modelling and commented on earlier drafts. JL provided technical assistance with the modelling and wrote up the study. BJ provided assistance on the costings. CS provided assistance related to the medical and epidemiological aspects.

All authors have read and approved the final manuscript.

\section{Competing interests}

This study was undertaken by persons who were on the salaried staff of the WHO at the time of the study. None of the authors have any competing interests.

Received: 29 April 2008 Accepted: 17 March 2010 Published: 17 March 2010

\section{References}

1. WHO: The World Health Report 2001. Mental Health; New Understanding, New Hope WHO Geneva 2001.

2. Johns B, Baltussen R, Hutubessy R: Programme costs in the economic evaluation of health interventions. Cost Eff Resour Alloc 2003, 1(1):1.

3. Adam T, Evans DB, Murray CJ: Econometric estimation of country-specific hospital costs. Cost Eff Resour Alloc 2003, 1(1):3.
4. Adam T, Koomanchap MA: Cost-effectiveness analysis: can we reduce variability in costing methods? Int J Tech Assess Health Care 2002, 19:407-20.

5. World Health Organization: Making choices in health: WHO guide to costeffectiveness analysis. WHO GenevaTan-Torres Edejer T, Baltussen R, Adam T, Hutubessy R, Acharya A, Evanns DB, Murray CJL 2003.

6. Murray CJ, Evans DB, Acharya A, Baltussen RM: Development of WHO guidelines on generalized cost-effectiveness analysis. Health Econ 2000, 9:235-51.

7. Hutubessy RC, Baltussen RM, Torres-Edejer TT, Evans DB: Generalised costeffectiveness analysis: an aid to decision making in health. Appl Health Econ Health Policy 2002, 1:89-95.

8. Baltussen RM, Hutubessy RC, Evans DB, Murray CJ: Uncertainty in costeffectiveness analysis. Probabilistic uncertainty analysis and stochastic league tables. Int J Technol Assess Health Care 2002, 18:112-9.

9. Hutubessy RC, Baltussen RM, Evans DB, Barendregt JJ, Murray CJ: Stochastic league tables: communicating cost-effectiveness results to decisionmakers. Health Econ 2001, 10:473-7.

10. Baltussen RM, Adam T, Tan Torres T, Hutubessy RC, Acharya A, Evans DB: Generalized Cost-Effectiveness Analysis: A Guide. Global Programme on Evidence for Health Policy Geneva, World Health Organization 2002.

11. Murray CJ, Lauer JA, Hutubessy RC, Niessen L, Tomijima N, Rodgers A, Lawes CM, Evans DB: Effectiveness and costs of interventions to lower systolic blood pressure and cholesterol: a global and regional analysis on reduction of cardiovascular-disease risk. Lancet 2003, 361:717-25.

12. WHO-CHOICE: Choosing Interventions that are Cost Effective. [http:// www.who.int/choice/en/, Accessed Feb 3rd 2010.

13. Baltussen R, Adam T, Tan-Torres Edejer T, Hutubessy R, Acharya A, Evans DB, Murray CJL: Chapter 1. What is Generalised Cost-Effectiveness Analysis? Making Choices in Health. WHO Guide to Cost-Effectiveness Analysis WHO GenevaTan-Torres Edejer T, Bltussen R, Adam T, Hutubessy R, Acharya A, Evans DB, Murray CJL 2003 .

14. WHO: The World Health Report 2002. Reducing Risks, Promoting Healthy Life WHO Geneva 2002.

15. Global Burden of Disease Regions used for WHO-CHOICE Analyses. WHO [http://www.who.int/choice/demography/regions/en/index.html], Accessed 11th November 2009

16. Fulfilling the potential of Cancer Prevention and Early Detection. National Cancer Policy Board, Institute of Medicine 2003 [http://www.nap. edu/books/ETC].

17. Lock K, Pomerleau J, Causer L, McKee M: Inadequate Fruit and Vegetable Consumption. Draft Sept 2001. European center on Health of Societies in Transition London School of Hygiene and Tropical Medicine, London.

18. Herrinton LJ, Selby JV, Friedman GD, Queensberry CP, Weiss NS: Casecontrol study of digital-rectal screening in relation to mortality from cancer of the distal rectum. Am J Epidemiol 1995, 142:961-4.

19. Pignone M, Rich M, Teutch SM, Berg AO, Lohr KN: Screeing for colrectal cancer in adults at average risk: A summary of evidence for the U.S. preventive services task force. Annals of Internal Medicine 2002, 137:132-41.

20. Winawer SJ, Fletcher RH, Miller L, Godlee F, Stolar MH, Mulrow CD, Woolf SH, Glick SN, Ganiats TG, Bond JH, Rosen L, Zapka JG, Olsen SJ, Giardiello FM, Sisk JE, Van Antwerp R, Brown-Davis C, Marciniak DA, Mayer RJ: Colorectal cancer screening: clinical guidelines and rationale. Gastroenterology 1997, 112:594-642, Published errata in Gastroenterology 1997; 112: 1060 and 1998; 114: 625

21. Byers T, Levin B, Rothenberger D, Dodd GD, Smith RA: American Cancer Society guidelines for screening and surveillance for early detection of colorectal polyps and cancer: update 1997. CA Cancer J Clin 1997, 47:154-60.

22. Fletcher RH: The end of barium enemas? N Engl J Med 2000, 342:1823-4.

23. Winawer SJ, Stewart ET, Zauber AG, Bond JH, Ansel H, Waye JD, Hall D, Hamlin JA, Schapiro M, O'Brien MJ, Sternberg SS, Gottlieb LS: A comparison of colonoscopy and double-contrast barium, enema for surveillance after polypectomy. National Polyp Study Work Group. N Engl I Med 2000, 342:1766-72.

24. Economics Research Service: United Nations Department of Agriculture. International Food Consumption Patterns [http://www.ers.usda.gov/Data/ InternationalFoodDemand/Index.asp?view=PEF\#IFD], Accessed November 9th 2009. 
25. Regmi A, Deepak MS, Seale JL, Bernstein J: Cross-Country Analysis of Food Consumption Patterns. Changing Structiure of Global Food Consumption and Trade/WRS-01-1 Economic Research Service USDA.

26. Norat T, Lukanova A, Ferrari P, Riboli E: Meat consumption and colorectal cancer risk: an estimate of attributable and preventable fractions. IARC. Nutrition and Lifestyle: Opportunities for Cancer prevention IARC Scientific Publications No 156. IARC, Lyon, FranceRiboli E, Lambert R 2002, 223-5.

27. Norat T, Lukanova A, Ferrari P, Riboli E: Meat consumption and colorectal cancer risk: dose-response meta-analysis of epidemiological studies. Int $\mathrm{J}$ Cancer 2002, 98:241-56.

28. IARC Handbooks of Cancer Prevention: Weight Control and Physical Activity. IARC Press, Lyon, France 2002, 6.

29. Schatzkin A, Lanza E, Corle D, Lance P, Iber F, Caan B, Shike M, Weissfeld J, Burt R, Cooper MR, Kikendall JW, Cahill J: Lack of effect of a low-fat, highfiber diet on the recurrence of colorectal adenomas. Polyp Prevention Trial Study Group. N Engl J Med 2000, 342:1149-55.

30. Frank L, Andersen $M, S$ Schmidt T: Obesity relationship with community design, physical activity, and time spent in cars. Am J Prev Med 2004, 27:87-96.

31. Ewing R, Schmid T, Killingworth R, Zlot A, Raudenbusch S: Relationship between urban sprawl and physical activity, obesity, and morbidity. Am $J$ Health Promotion 2003, 18:47-57.

32. Surgeon General: The Health Consequences of Smoking. A report of The Surgeon General. Executive Summary CDC, Atlanta 2004.

33. IARC Handbooks of Cancer Prevention: Non-Steroidal Anti-Inflammatory Drugs Volume 1. IARC Press, Lyon, France 1997.

34. Eichholzer M, Luthy J, Moser U, Fowler B: Folate and the risk of colorectal, breast and cervix cancer: the epidemiological evidence. Swiss Medical Weekly 2001, 131:539-49.

35. Towler BP, Irwig L, Glasziou P, Weller D, Kewenter J: Screening for Colorectal Cancer Using the Faecal Occult Blood Test, Hamoccult (Cochrane Review). The Cochrane Library Chichester, UK: John Wiley \& Sons, Ltd 2003, 4.

36. Mandel JS, Church TR, Bond JH, Ederer F, Geisser MS, Mongin SJ, Snover DC, Schuman LM: The effect of fecal occult-blood screening on the incidence of colorectal cancer. N Engl J Med 2000, 343:1603-7.

37. SEER cancer registry data. [http://seer.cancer.gov/faststats/selections.php], Accessed 4th March 2004.

38. Rex DK, Smith JJ, Ulbright TM, Lehman GA: Screening colonoscopy in asymptomatic average-risk persons with negative fecal occult blood tests. Gastroenterology 1991, 100:64-7.

39. Disario JA, Foutch PG, Mai HD, Pardy K, Manne RK: Prevalence and Malignant Potential of Colorectal Polyps in Asymptomatic, Average-Risk Men. American Journal of Gastroenterology 1991, 86:941-5.

40. Johnson DA, Gurney MS, Volpe RJ, Jones DM, VanNess MM, Chobanian SJ, Avalos JC, Buck JL, Kooyman G, Cattau EL Jr: A prospective study of the prevalence of colonic neoplasms in asymptomatic patients with an agerelated risk. Am J Gastroenterol 1990, 85:969-74.

41. Arminski TC, MCClean DW: Incidence and Distribution of Adenomateous Polyps of the Colon and Rectum based on 1,000 Autopsy Examinations. Dis Colon Rectum 1964, 19:249-61.

42. Blatt L: Polyps of the colon and rectum. Dis Colon Rectum 1961, 4:277-82.

43. Rickert RR, Auerbach O, Garfinkle L, Hammond EC, Frasca JM: Adenomatous lesions of the large bowel. An Autopsy Survey. Cancer 1979, 43:1847-57.

44. Correa P, Strong JP, Reif A, Johnston WD: The Epidemiology of Colorectal Polyps. Cancer 1977, 39:2258-64.

45. Stemmerman GN, Yatani R: Diverticulosis and polyps of the large intestine. Cancer 1973, 31:1260-70.

46. Chapman I: Adenomatous polypi of large intestine: incidence and distribution. Ann Surg 1963, 157:223-6.

47. Wagner J, Tunis S, Brown M, Ching A, Almeida R: Cost-effectiveness of colorectal cancer screening in average risk adults. Prevention and early detection of colorectal cancer London. SaundersYoung G, Rozen P, Levin B 1996, 321-56.

48. Wagner JL, Beheny CJ, Tunis SR, Ching A: US Congress, Office of Technology Assessment, Cost-effectiveness of Colorectal Cancer Screening in Average-Risk Adults, OTA-BP-H-146. Washington, DC: U.S. Government Printing Office 1995.
49. Bolin TD, Korman MG, Stanton R, Talley N, Newstead GL, Donnelly N, et al: Positive cost effectiveness of early diagnosis of colorectal cancer. Colorectal disease 1999, 1:113-22.

50. Selby JV, Friedman GD, Queensberry CP, Weiss NS: A case-control study of screening sigmoidoscopy and mortality from colorectal cancer. N Engl J Med 1992, 326:653-7.

51. Eddy DM, Nugent FW, Eddy JF, Coller J, Gilbertsen V, Gottlieb LS, Rice R, Sherlock $P$, Winawer S: Screening for colorectal cancer in a high-risk population. Results of a mathematical model. Gastroenterology 1987, 92:682-92.

52. Ladabaum U, Chopra CL, Huang G, Scheiman JM, Chernew ME, Fendrick AM: Aspirin as an adjunct to screening for prevention of sporadic colorectal cancer. A cost-effectiveness analysis. Ann Intern Med 2001, 135:769-81.

53. Rubin PH, Waye JD, Colonoscopic Polypectomy: A critical review of the literature. Current Gastroenterology Reports 2006, 8;5:430-433.

54. Winawer SJ, Zauber AG, Ho MN, O'Brien MJ, Gottleib LS, Sternberg SS, Waye JD, Schapiro M, Bond JH, Panish JF, Ackroyd F, Shike M, Kurtz RC, Hornsby-Lewis L, Gerdes H, Stewart ET, the National Polyp Study Workgroup: Prevention of colorectal cancer by colonoscopic polypectomy. The National Polyp Study Workgroup. N Engl JMed 1993, 329;27:1977-1981.

55. Dixon H, Borland R, Segan C, Stafford H, Sindall C: Public Reaction to Victoria's 2 Fruit ' $n$ ' 5 Veg Every Day' Campaign and Reported consumption of Fruit and Vegetables. Preventive medicine 1998, 27:572-82.

56. Vijan S, Hwang EW, Hofer TP: Which Colon Cancer Screening test? A comparison of Costs, Effectiveness, and Compliance. The American Journal of Medicine 2001, 111:593-601.

57. Eddy DM: Screening for Colorectal cancer. Annals of Internal Medicine 1990, 113:373-84.

58. Sonnenberg A, Delco F, Inadomi JM: Cost-effectiveness of colonoscopy in screening for colorectal cancer. Ann Intern Med 2000, 133:573-84.

59. O'Leary BA, Olynyk JK, Neville AM, Platell CF: Cost-effectiveness of colorectal cancer screening: Comparison of community-based flexible sigmoidoscopy with fecal occult blood testing and colonoscopy. Journal of Gastroenterology and Hepatology 2004, 19:36-47.

60. Frazier AL, Colditz GA, Fuchs CS, Kuntz KM: Cost-effectiveness of screening for colorectal cancer in the general population. JAMA 2000, 284:1954-61.

61. Berchi C, Bouvier V, Réaud J-M, Launoy G: Cost-effectiveness analysis of two strategies for mass screening of colorectal cancer in France. Health Economics 2004, 13:227-38.

62. Khandker RZ, Dulski JD, Kilpatrick JB, Ellis RP, Mitchell JB, Baine WB: A decision model and cost-effectiveness analysis of colorectal cancer screening and surveillance guildelines for average-risk adults. Int J Tech Assess in Health Care 2000, 16;3:799-810.

63. Loeve F, Brown ML, Boer R, van Ballegooijen M, van Oortmarssen GJ, Habbema JFD: Endoscopic colorectal-cancer screening, a cost-saving analysis. Journal of the National Cancer Institute 2000, 92:557-63.

64. Loeve F, Boer R, van Oortmarssen GJ, van Ballegooijen M, Habbema JDF: The MISCAN-COLON Simulation Model for the Evaluation of Colorectal CancerScreening. Computers and Biomedical Research 1999, 32:13-33.

65. Geul KW, Bosman FT, van Blankenstein M, Grobbee DE, Wilson JHP: Prevention of Colorectal Cancer. Costs and Effectiveness of Sigmoidoscopy. Scand J Gastroenterol 1997, 32(Suppl 223):79-87.

66. Lieberman DA: Cost-effectiveness model for colon cancer screening. Gastroenterology 1995, 109:1781-90.

67. Lejeune C, Arveux P, Dancourt V, Fagnani F, Bonithon-Kopp C, Faivre J: A simulation model for evaluating the medical and economic outcomes of screening strategies for colorectal cancer. European Journal of Cancer Prevention 2003, 12:77-84

68. Ness RM, Holmes AM, Klein R, Dittus R: Cost-Utility of One-Time Colonoscopic Screening for Colorectal Cancer at Various Ages. American Journal of Gastroenterology 2000, 95:1800-11.

69. Salkeld G, Young G, Irwig L, Haas M, Glasziou P: Cost-effectiveness analysis of screening by faecal occult blood testing for colorectal cancer in Australia. Aust N Z J Public Health 1996, 20:138-43.

70. Wagner J, Herdman RC, Wadhwa S: Cost effectiveness of Colorectal Cancer Screening in the Elderly. Annals of Internal Medicine 1991, 115:807-17. 
71. Tsuji I, Fukao A, Shoji T, Kuwajima I, Sugawara N, Hisamichi S: Costeffectiveness Analysis of Screening for Colorectal Cancer in Japan. Tohoku J Exp Med 1991, 164:269-78.

72. Leshno M, Halperin Z, Arber N: Cost-effectiveness of Colorectal cancer Screening in the Average Risk Population. Health Care Management Science 2003, 6:165-74.

73. Neilsen AR, Whynes D: Cost-effectiveness of screening for colorectal cancer: A simulation model. IMA Journal of Mathematics Applied in Medicine \& Biology 1995, 12:355-67.

74. Results of the first round of a demonstration pilot of screening for colorectal cancer in the United Kingdom: UK Colorectal Cancer Screening Pilot Group. BMJ 2004, 329(7458):133, Epub 2004 Jul 5.

75. Atkin WS, Hart A, Edwards R, McIntyre P, Aubrey R, Wardle J, Sutton S, Cuzick J, Northover JM: Yield of neoplasia, and adverse effects of flexible sigmoidoscopy screening. Gut 1998, 42:560-5.

76. Spratt JS Jr, Spjut HJ: Prevalence and prognosis of individual clinical and pathologic variables associated with colorectal carcinoma. Cancer 1967, 20:1976-85.

77. Mathers CD, Shibuya K, Boschi-Pinto C, Lopez AD, Murray CJL: Global and regional estimates of cancer mortality and incidence by site: 1 . Application of regional cancer survival model to estimate cancer mortality distribution by site. BMC Cancer 2002, 2:36.

78. Shibuya K, Mathers CD, Boschi-Pinto C, Lopez AD, Murray CJ: Global and regional estimates of cancer mortality and incidence by site: II. Results for the global burden of disease 2000. BMC Cancer 2002, 2:37.

79. Lauer JA, Murray CJL, Roehrich K, Wirth H: PopMod: a longitudinal population model with two interacting disease states. Cost Effectiveness and Resource Allocation 2003, 1:6 [http://www.resource-allocation.com].

80. Brown ML, Klabunde CN, Mzsliwiec P: Current capacity for endoscopic colorectal cancer screening in the United States: Data from the national cancer institute survey of colorectal cancer screening practices. Am J Med 2003, 115:129-33.

81. Baltussen R, Adam T, Tan-Torres Edejer T, Hutubessy R, Acharya A, Evans DB, Murray CJL: Chapter 4. Health effects. Making Choices in Health. WHO Guide to Cost-Effectiveness Analysis WHO GenevaTan-Torres Edejer T, Bltussen R, Adam T, Hutubessy R, Acharya A, Evans DB, Murray CJL 2003.

82. Memorial Sloan-Kettering Camcer Center: Surgery. Common Preoperative work-up. [http://www.mskcc.org/mskcc/html/1928.cfm], Accessed 15th July 2004.

83. Laparoscopic Resection of Colonic Carcinoma: EAES consensus conference Lisbon, June 2, 2002 Consensus Proceedings.

84. Morton G, Bowler I: Combined spinal-epidural as an alternative method of anaesthesia for a sigmoid-colectomy. Anaesthesia 2001, 56:799-820.

85. International Drug Price Indicator Guide: MSH, Arlington Virginia 2003.

86. British National Formulary No 47: Published by the British Medical Association, London and the Royal Pharmaceutical Society of Great Britain, London 2004.

87. WHO Commission on MacroEconomics and Health: Macroeconomics and health: investing in health for economic development. Report of the commission on Macroeconomics and Health Geneva: World Health Organization 2001

88. Gyrd-Hannsen D: Fecal occult blood tests. A cost-effectiveness analysis. Int J Technol Assess Health Care 1998, 14:290-301.

89. Brown ML, Fintor L: Cost-effectiveness of breast cancer screening: preliminary results of a systematic review of the literature. Breast Cancer Res Treat 1993, 25:113-8.

90. Guittet L, Bouvier V, Mariotte N, Vallee JP, Levillian R, Tichet J, Launoy G: Comparison of a guaiac and an immunochemical feacal occult blood test for the detection of colonic lesions according to lesion type and location. Br J Cancer 2009, 100;8:1230-5, Epub 2009, Mar 31.

91. Dancourt V, Lejeune C, Lepage C, Gailliard MC, Meny B, Faivre J: Immunochemical faecal occult blood tests are superior to guaiac-based tests for the detection of colorectal neoplasms. Eur J Cancer 2008, 44(15):2254-8.

92. Castaglione G, Zappa M, Grazzini G, Mazzotta A, Blagini M, Salvadori P, Ciatto S: Immunochemical vs guaiac faecal occult blood tests in a population-based screening programme for colorectal cancer. $\mathrm{Br} J$ Cancer 1996, 74:141-144.

93. Boer R, deKonig HJ, van Ballegooijen M, Maas van der PJ: Important Influences on Effectiveness and Costs to Be Considered in the Evaluation of Cancer Screening. Quantitative Methods of Evaluation of
Cancer Screening, Arnold, a member of the Hodder Headline Group London Oxford University Press, New YorkDuffy S, Hill C, Esteve J 2001, 13-25.

94. Redaelli A, Cranor CW, Okano GJ, Reese PR: Screening, Prevention and Socioeconomic costs associated with the treatment of colorectal cancer. Pharmacoeconomics 2003, 21:1213-35.

doi:10.1186/1478-7547-8-2

Cite this article as: Ginsberg et al:: Prevention, screening and treatment of colorectal cancer: a global and regional generalized cost effectiveness analysis. Cost Effectiveness and Resource Allocation 2010 8:2.

\section{Submit your next manuscript to BioMed Central and take full advantage of:}

- Convenient online submission

- Thorough peer review

- No space constraints or color figure charges

- Immediate publication on acceptance

- Inclusion in PubMed, CAS, Scopus and Google Scholar

- Research which is freely available for redistribution 